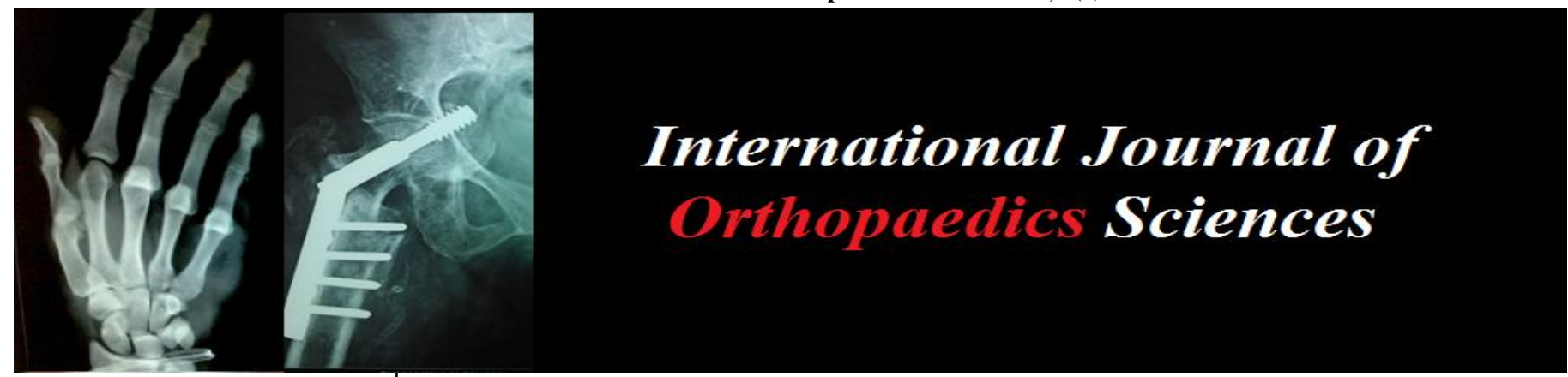

ISSN: $2395-1958$

IJOS 2017; 3(3): 1041-1044

(C) 2017 IJOS

www.orthopaper.com

Received: 21-05-2017

Accepted: 22-06-2017

Dr. P Balasubramaniyan Assistant Professor, Department Of Orthopedics, Government Thoothukudi Medical College, Thoothukudi, Tamil Nadu, India

Dr. Ashokan C

Associate Professor,

Department Of Orthopedics, Government Stanley Medical College, Tamil Nadu, India, India

Dr. Kathir Azhagan S Resident Department of Orthopedics, Government Stanley Medical College, Tamil Nadu, India
Correspondence Dr. Ashokan C Associate Professor, Department Of Orthopedics, Government Stanley Medica College, Tamil Nadu, India, India

\section{Evaluation on the outcome of management of infected Nonunion and Gap Nonunion fracture of long bones by Ilizarov method}

\author{
Dr. P Balasubramaniyan, Dr. Ashokan C and Dr. Kathir Azhagan S
}

DOI: https://doi.org/10.22271/ortho.2017.v3.i3o.151

\section{Abstract}

Subcutaneous bones like tibia are susceptible to compartment syndrome, wound infection, non-union, deformities, shortening and other problems. Duration of treatment and the cost of treatment of infected non-union and gap non-union causes a huge burden to the patient as well as to the treating institution. Distraction osteogenesis is a novel technique by which new bones can be created in the bone defects, limb lengthening to compensate shortening, rotational deformities can be corrected, soft tissue loss can be dealt with progressive histogenesis

Keywords: Management, infected Nonunion, Gap Nonunion fracture, Ilizarov method

\section{Introduction}

Infected non-union is one of the greatest problems in orthopaedic surgeries. The incidence of infected non-union and gap non-union of fractures of long bone is increasing in India due to road traffic accidents. Moreover infected non-union and gap non-union of fracture of long bones is not a single problem, it is associated with multiple problems like long standing infection associated with organism resistant to most of commonly used antibiotics, bone loss due to extensive debridement or primary bone loss at the site of injury, soft tissue loss. There are various treatment modalities available for treatment available for treatment of infected nonunion and gap non-union of fracture of long bones. Treatment modalities like wound debridement and external fixation with AO external fixator, antibiotic coated nailing, limb reconstruction system, Ilizarov ring fixation etc., but each method has its own merits and demerits.

\section{Aims and Objectives}

To evaluate the outcome on the management of infected non-union and gap non-union fractures of long bones by Ilizarov method.

\section{Materials and Methods}

This is a prospective study conducted at The Department of Orthopaedics, Govt. Stanley Medical college \& Hospital, Chennai -01 during the period August 2015 to July 2016. Patients admitted with infected non-union fracture of long bones and Gap non-union of long bones due to various causes and was treated with Ilizarov ring fixation method and were studied for the functional outcome, complications, fracture union.

\section{Inclusion Criteria}

- $\quad$ Age more than 18 years.

- $\quad$ Both Genders.

- Patient presented with infected non-union fracture of long bones

- Fracture of long bones with bone defect due to trauma, wound debridement, segmental bone loss due to resection of bone tumours. 


\section{Exclusion Criteria}

- Patients aged less than 18 years.

- Patient with psychotic disorders.

- Patient unwilling for long term treatment and uncooperative for post-operative rehabilitation

\section{Methods}

- General information like Name, Age, Sex, Occupation, Address were noted.

- Mode of injury like Motor vehicle accident, Assault, previous surgeries for infected non-union of fractures, industrial injury, etc were collected

- General examination like Anemia, Jaundice, lymphadenopathy, blood pressure was noted.

- Systemic examination like Cardiovascular system, respiratory system was examined

- Open fractures of long bones with bone defect and infected non-union of fractures were debrided and skeletal stabilisation done using AO external fixator.

- Large soft tissue loss was treated with split skin grafting and myocutaneous flap by the plastic surgeon.

- Infected non-union of fractures of long bones were classified using Paley 's modification of ILIZAROV'S classification of infected non-union of fractures of long bones and Kulkarni classification of infected non-union fracture of long bones.

- $\quad$ All patients have preoperative $X$ rays of the affected limb for the assessment of level of fracture, type of non-union, rotational deformities, shortening and bone defects.

- Culture swab taken from the wounds and treated with intravenous antibiotics according to the sensitivity pattern.

- Preoperative counselling given to the patient regarding the mode of treatment, Duration of treatment and postoperative rehabilitation and complication related to the surgery.

- Ilizarov ring fixator was constructed on the previous day and sent for sterilization.

- Under subarachnoid block involved limb painted and draped pre-constructed Ilizarov ring was introduced into the limb and fixed with $\mathrm{K}$ - wires and tensioned adequately using wire tensioner and schantz pin. Hybrid Ilizarov method using wires and half pins was followed in most of cases.

- Corticotomy was done if necessary and fibular osteotomy in case of bone transport and bone transport was done after the latency period of

- Distraction was done at the rate of $1 \mathrm{~mm} /$ day and rhythm $0.25 \mathrm{~mm}$ every 6 th hourly.

- Patient were mobilised with partial weight bearing immediately and full weight bearing once tolerated. Method of Distraction of bone segment, Pin site care, joint mobilisation exercises were taught and patient discharged.

- $\quad$ Routine Follow up done at monthly intervals with X rays for assessment of fracture healing, quality of regenerate in distraction osteogenesis and to assess any deformity.

- After completing the bone transport, patient is kept on ring fixator till satisfactory union is achieved.

- If there is any deformity, then realignment of fixator was done accordingly.

- Dynamisation of the fixator was done to achieve union at the docking site.

- Fracture healing assessed radiologically by appearance of bony trabecules at the fracture in atleast three of four cortices in AP and lateral views, clinically by absence of pain and absence of abnormal mobility.

- Once the fracture healed ilizarov fixator was removed after releasing the wire tension and plaster of Paris cast was applied for a period of six weeks and cast was removed then patient allowed to bear weight.

- Results were assessed using the criteria laid dowm by ASAMI (The Association for Study and Application of the Methods of Ilizarov) scoring system.

\section{Evaluation of the Outcome}

For evaluating the results oftreatment of infected non-union and gap non-union of fractures by Ilizarov method, we used the Association for the Study and Application of the Methods of Ilizarov (ASAMI) scoring system.

It has two components:

1. Bone Results

2. Functional Results

\section{Bone Results}

\begin{tabular}{|c|c|}
\hline Excellent & $\begin{array}{c}\text { Unoin,No infection, }<7 \text { degree deformity,Limb length } \\
\text { inequality }<2.5 \mathrm{~cm}\end{array}$ \\
\hline Good & $\begin{array}{c}\text { Union + any two of the following: No } \\
\text { infection,Deformity }<7 \text { degree, Limb length } \\
\text { discrepancy }<2.5 \mathrm{~cm}\end{array}$ \\
\hline Fair & $\begin{array}{c}\text { Union + only one of the following }: \text { no infection, } \\
\text { deformity }<7 \text { degree, limb length discrepancy, } 2.5 \mathrm{~cm}\end{array}$ \\
\hline Poor & $\begin{array}{c}\text { Non union/ refracture/ union+ infection+ deformity }>7 \\
\text { degree + limb length discrepancy }>2.5 \mathrm{~cm}\end{array}$ \\
\hline
\end{tabular}

\section{Functional Results}

Based on the five criteria

1. Obsevable limp

2. Stiffness (loss of $>15$ degree of knee extension and or $>$ 15 degree of ankle dorsiflexion)

3. Reflex sympathetic dystrophy

4. Pain that reduced activity or disturbed sleep

5. Inactivity (due to unemployment or Inability to carry out daily activities)

The functional results were classified as follows

Excellent- If the patient is active, able to do his / her daily activities, and absence of other four criteria.

Good - If the patient is active but one or two of the other criteria are present.

Fair -If the patient is active, with the presence of three or four of the other criteria.

Poor - If the patient is inactive, regardless of the presence of other criteria.

\section{Observation and Results}

\section{Age Distribution}

\begin{tabular}{|c|c|c|}
\hline Age in years & No. Of cases & Percentage \\
\hline $11-20$ & 2 & $10 \%$ \\
\hline $21-30$ & 7 & $35 \%$ \\
\hline $31-40$ & 3 & $15 \%$ \\
\hline $41-50$ & 5 & $25 \%$ \\
\hline $51-60$ & 3 & $15 \%$ \\
\hline
\end{tabular}




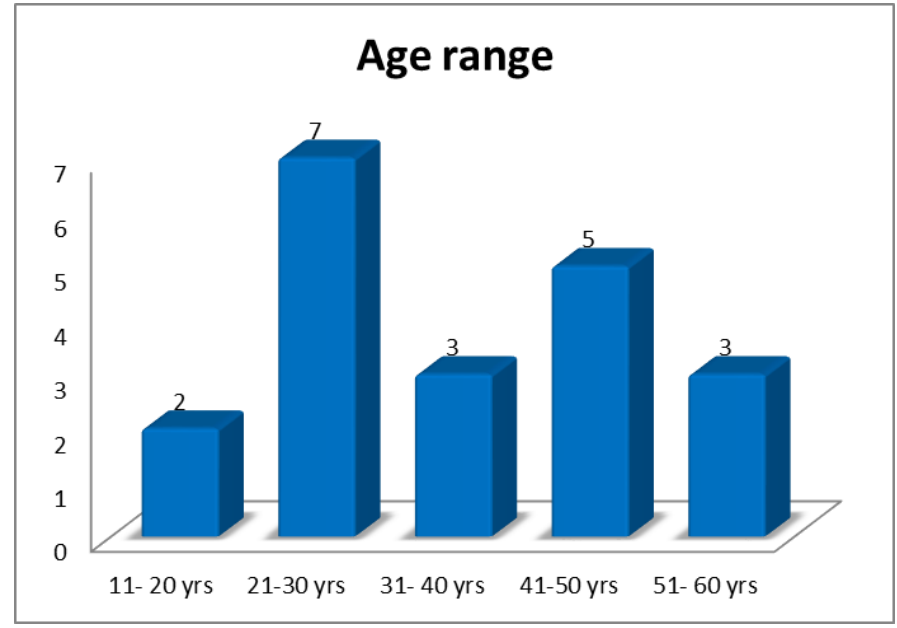

The age group varies from 18 years to 60 years with maximum incidence between 21 to 30 years mostly the young individuals.

\section{Sex Distribution}

Among 20 patients included in this study, males were predominant accounting to 18 numbers.

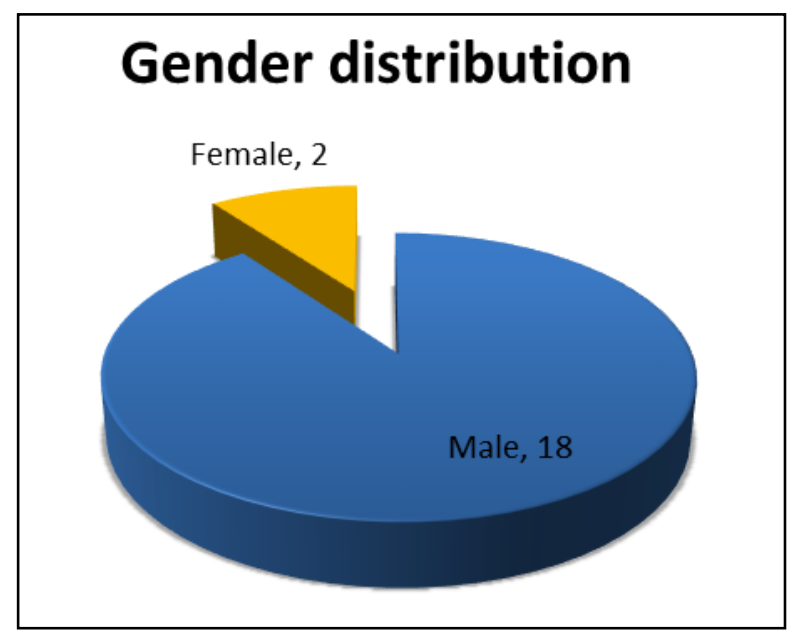

\section{Side of Injury}

In our study, left side of the limb is common.

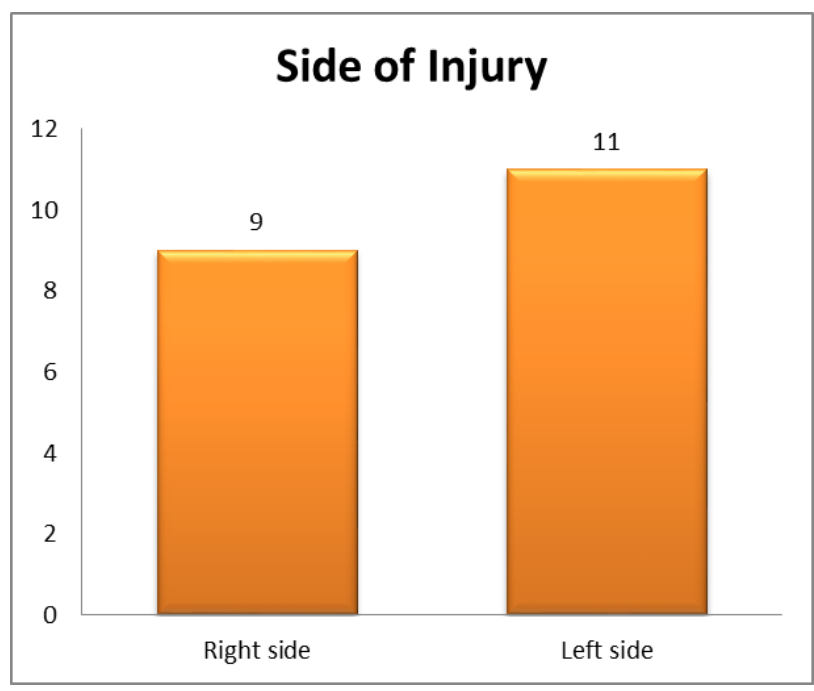

IV. Mode of Injury

The most common mode of injury is road traffic accident. Only one case is due to chronic osteomyelitis, sequestrectomy done and the defect was treated with Ilizarov bone transport.

\begin{tabular}{|c|c|c|}
\hline Mode of injury & Mode of Injury & Percentage \\
\hline Road Traffic Accident & 19 & 95 \\
\hline Infection & 1 & 5 \\
\hline Industrial Injury & 0 & 0 \\
\hline Assault & 0 & 0 \\
\hline
\end{tabular}

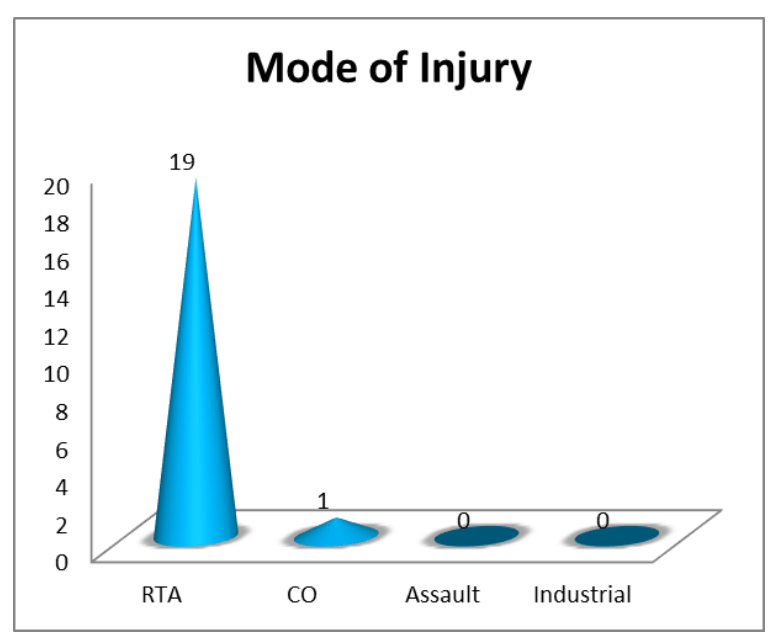

V. Classification

In our study, most of the cases belongs to Umairov's type IV.

\begin{tabular}{|c|c|c|}
\hline & Classification of Injury & Percentage \\
\hline Type I & 3 & $15 \%$ \\
\hline Type II & 2 & $10 \%$ \\
\hline Type III & 1 & $5 \%$ \\
\hline Type IV & 14 & $70 \%$ \\
\hline
\end{tabular}

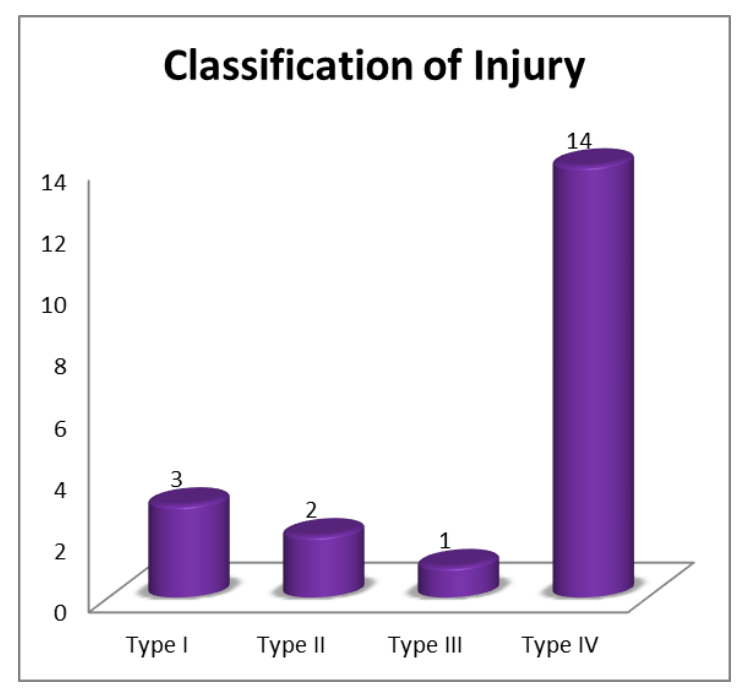

\section{Associated Injuries}

1. Fracture of Opposite tibia- 1 case

2. Fracture of shaft of femur -2 cases

3. Intertrochanteric fracture- 1 case

4. Foot injuries-1 case

\section{Number of Previous Surgeries}

\begin{tabular}{|c|c|c|}
\hline No. Of previous surgery & No. Of cases & Percentage \\
\hline 1 & 6 & $30 \%$ \\
\hline 2 & 12 & $60 \%$ \\
\hline 3 & 0 & 0 \\
\hline 4 & 2 & $10 \%$ \\
\hline
\end{tabular}




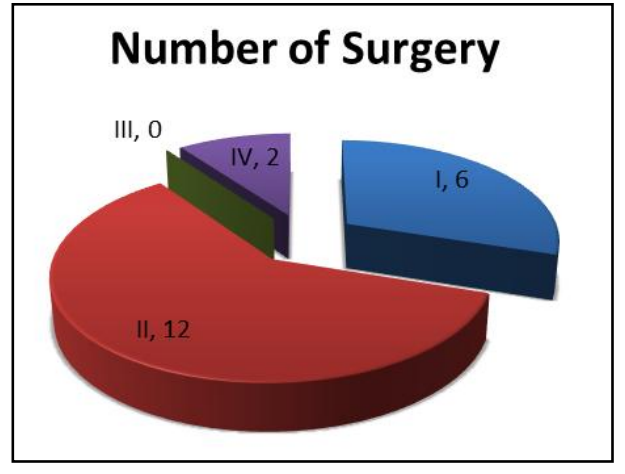

The modal distribution of previous surgeries in our study group is 2 .

\section{Duration of Treatment}

The duration of treatment varies from minimum of 5 months to maximum of 13 months with mean duration of 8.8 months.

\section{Complications}

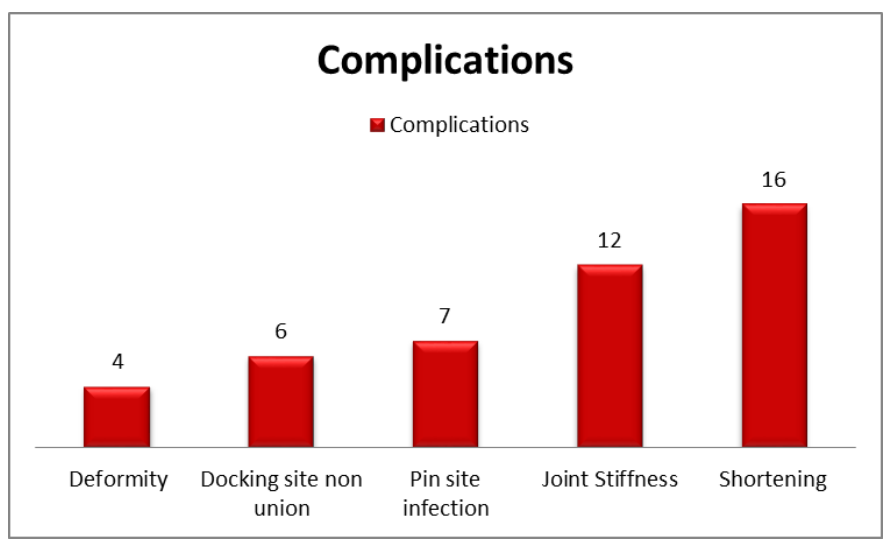

Among the complications, shortening is the most common complication which constitutes $80 \%$ of cases, and the average shortening was about $2 \mathrm{~cm}$ which was within the acceptable limit. The second common complication in the study was joint stiffness which constitutes $60 \%$ mostly equines deformity.

\section{Outcome}

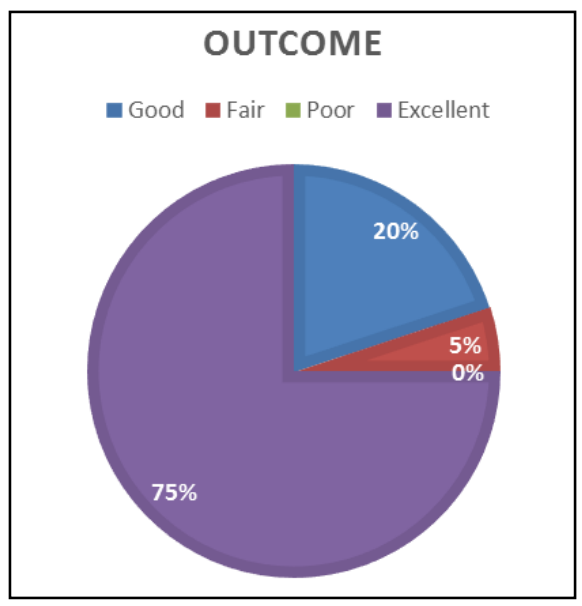

75 percent of the patients had an excellent outcome while no patient suffered from poor outcome

\section{Conclusion}

From our observation it is proved that Ilizarov ring fixation is a versatile technique in treatment of infected non-union and gap non-union of fracture of long bones. Majority of the patient had an excellent outcome with regards to deformities, shortening, limb length discrepancies, rotational deformities soft tissue defects etc. Ilizarov ring fixation addressed all these problems simultaneously and successfully

\section{Reference}

1. Biomechanics of the Ilizarov External fixator, Dror Paley- Orthopaedic principles of Ilizarov-A.S.A.M.I

2. Biomechanics of the Ilizarov techinique-CORR, 1989; 241:97.

3. Codivilla. The Orthopaedic clinics of North America; by Vladimir Schwarstman, 1900; 21(4).

4. Green SA, Harris NL, isakanian J. The Rancho mounting techinique for the Ilizarov method, 1992.

5. Ilizarov GA, Harris NL, shakian IJ. The Rancho mounting techinique for the Ilizarov method, 1992.

6. Kulkarani GS. Text book of orthopaedics and TRAUMA Jaypee Brothers New Delhi Biomechanics of Ilizarov Ring Fixator. 1999, 2.

7. Umairov GA. Classification of non-union of the long bones complicated by infection and the principles of treatment, 1986.

8. Paley D Current Techiniques Of Limb Lengthening Ilizarov treatment of tibial non-union with bone loss.

9. Management of Infected non-union, tibial fractures with ilizarov external fixator, - journal of evidence based medicine - Nageshwar Rao. A.M. Ilias Basha.

10. Evaluation of management of tibial non-union with Ilizarov fixation, journal Ayub medical college Abbottabad Faramanullah, muhammed shoaiah khan. 2007; 19(3).

11. Paley D Catagni, Aragnani MA, Villia F, Benedectti A, Cattaneo GB, Ilizarov r. treatment of tibial non-union with bone loss. Clin orthop related research. 1989; 24:146, 65.

12. Cattaneor, Catagni $\mathrm{m}$, Johnson ef. treatment of infected non-union and segmental defect of tibia by Ilizarov.

13. Ilizarov techiniques; To study the results of infected nonunion of tibia, article-The Professional Medical journal.

14. Ilizarov GA. The tension stress effect on the genesis and growth of tissues. Part I - The influence of stability of fixation of soft tissues preservation. Clin ortop. 1989

15. Text book of Ilizarov surgical techiniques - bone correction and lengthening by Vladimir Golyakhovsky, Moscow, Russia by Jaypee Publishers.

16. Arason J. symposium - biological and clinical evaluation of distraction osteogenesis. Clinical orthop, 1994.

17. Green SA. The ilizarov method; Rancho mounting techiniques. Orthoop clin North America, 1991.

18. ASAMI group. non-union, limb lengthening, Aarson editors, Operative principles of Ilizarov. 